\title{
Effect of stacking sequence on the erosive wear behavior of jute and jute- glass fabric reinforced epoxy composite
}

\author{
B.C. Patel ${ }^{1}$, S.K. Acharya ${ }^{2 *}$, D. Mishra ${ }^{3}$ \\ ${ }^{1}$ Department of Mechanical Engineering, SEC, Sundargarh,INDIA \\ ${ }^{2 *}$ Department of Mechanical Engineering, National Institute of Technology, Rourkela-769008, Orissa, INDIA \\ ${ }^{3}$ Department of Mfg.Sc. \& Engg, VSSUT, Burla, Sambalpur, INDIA \\ "Corresponding Author: email : drsamirka@yahoo.com
}

\begin{abstract}
In this present work the effect of stacking sequence on erosive wear behavior of untreated woven jute and glass fabric reinforced epoxy hybrid composites has been investigated experimentally. Composite Laminates were fabricated by hand lay-up technique in a mold and cured under light pressure for one hour, followed by curing at room temperature for forty eight hours. All the laminates were made with a total of 4 plies, by varying the number and position of glass layers so as to obtain six different stacking sequences. One group of only jute laminate was also fabricated for comparison purpose. The erosion rates of these composites have been evaluated at different impingement angles $\left(30-90^{\circ}\right)$ and at three different particle speeds $(\mathrm{v}=48,70$, $82 \mathrm{~m} / \mathrm{s}$ ). The erodent used is silica sand with the size range $150-250 \mu \mathrm{m}$ of irregular shapes. The impingement angle was found to have a significant influence on the erosion rate. The composite material showed semi ductile behaviour with maximum erosion at $45^{0}$ impingement angle. The morphology of the eroded surface was examined by SEM.It is conclude from the study that the erosive wear behavior of natural fiber jute can be improved significantly by hybridizing with synthetic fiber glass.
\end{abstract}

Keywords: Bagasse fiber, SiC abrasive paper, abrasive wear, SEM

\section{Introduction}

When a local damage caused with material removal by impingement of solid particle against a target surface, material loss occurs, this generally referred to as erosive wear. Popularity of polymer composites in the present scenario is mainly because of their high specific strength and stiffness. These composites are gaining wide acceptance, particularly in aerospace applications for their low weight, high strength to weight ratios and their capabilities to withstand high temperature. However these composites are now getting used in tribo applications such as bearing and gears etc. Being used in applications such as radomes, surfing boats, gas and steam turbine blades, gears of locomotives, conveyer belts, pump impellers in mineral slurry processing, where the components encounter impact of lot of abrasion like dust, sand, splinters of materials, slurry of solid particles and consequently the materials, under go erosive wear (Rajesh et al, 2001). The erosive resistance of polymer composite is low in comparison to metallic materials (Roy et al, 1994). It is also established that erosive wear of reinforced polymer composite is usually higher than unreinforced polymer matrix (Hager et al, 1995). Visualizing the importance of polymeric composites, lot of work has been done to evaluate various types of polymers and their composites to solid particle erosion (Harsha and Thakre, 2007; Tiwari et al, 2003; Bijwe et al, 2001; Bijwe et al, 2002). Most of these workers have carried out wide range of thermoset and thermoplastic PMCs having glass, carbon, graphite and Kevlar fibers in the form of tape, fabric and chopped mat as reinforcement.

Sabeel and Vijayarangan (2008) studied the effect of stacking sequence on tensile, flexural and inter laminar shear properties of woven jute-glass fabric reinforced isothalic polyester composites and reported that incorporation of glass in jute fibre composites enhances the properties of resulting hybrid composites and the layering sequence (altering the position of glass plies) significantly affects the flexural and inter laminar shear strength. Recently, Santulli and Caruso (2009) studied the comparison between two composite architectures namely a hemp/epoxy random mat and a jute/epoxy plain weave laminate, both with $45 \pm 2 \%$ volume and their work reported that manufacturing a hybrid laminate, using jute/epoxy plain woven and hemp/epoxy random mat, most 
preferably the latter (inherently stronger) as skins and the former as core, would be able to reduce the scattering in impact resistance values and lead to a better predictability of its impact behaviour.

Srivastava et al. (1988) investigated about the fracture toughness and fracture surface energy of epoxy, epoxy/fly-ash, epoxy/carbon, fibre, epoxy/ carbon fiber/fly-ash, epoxy/glass fiber and epoxy/glass fiber/fly-ash composites. Their results showed that a fly-ash particle can arrest the crack path and thus improve the fracture properties of fiber reinforced plastic (FRP) composites. Miyazaki and Takeda (1993) studied about effect of matrix materials, reinforcement fibers, interface strength between matrix material and fibers, impact angle, and particle velocity on the solid particle erosion behavior of short glass carbon fiber reinforced nylon 66 resin, ABS resin .They found that the erosion rate is larger in FRP, that in neat resin and the erosion rate of FRP decreases with the increase of interface strength between matrix material and fibers.

After reviewing the existing literature available on natural fiber particularly jute fiber it is found that mechanical properties of jute fiber composite are much lower than those of synthetic fiber composite. Another disadvantage which makes jute fiber less attractive is the poor resistance to moisture absorption. Hence use of jute fiber alone in polymer matrix is inadequate in satisfactorily tackling all the technical needs of a fiber reinforced composite.

With this back ground the priority of this work is to develop a superior, but economical composite with jute fiber which can be combined with a synthetic fiber that is glass in the same matrix material so as to take the best advantage of the properties of both fibers. It is also planned to study the mechanical properties and erosive wear behavior of the composite. Resistance to erosive wear is influenced by different factors like particle size (Neville et al, 2005), velocity impingement (Sari and Sinmazcelik, 2007), hardness (Hussainova et al, 1999), impingement angle (Das et al, 1999), fiber length and fiber content (Barkoula and Karger, 2002) and also with the environment (Das et al, 2006). Hence, it was thought worthwhile to investigate the erosive wear behaviour of jute and glass fiber reinforced hybrid polymer composite. Based on the above works, the current work aims at finding out the potential of hybridization of jute and glass fiber for tribological applications. The effect of hybridization of glass and layering sequence effect on erosive wear behavior of woven jute-glass fiber hybrid composite is studied.

\section{Preparation of Composites}

Hybrid laminates of woven jute and glass mat were prepared by hand lay-up technique. The type of epoxy resin used in the present investigation is LY 556which chemically belongs to the 'epoxide' family. Its common name is Bisphenol-A-iglycidylEther. It possesses a density of $1.1 \mathrm{gm} / \mathrm{cm} 3$. The low temperature epoxy resin and corresponding hardener (HY951) aresupplied by Ciba- Geigy of India Limited. Epoxy is mixed with hardener in the ratio 10:1 by weight. A wooden mold of dimension $(150 \times 60 \mathrm{x}$ 5) mm was used for casting the composite sheet. A coat of gel was applied on the inner side of the mold and mold release spray was used for quick and easy removal of the composite sheet. Usual hand lay-up technique was used to manufacture the composite sheet of $5 \mathrm{~mm}$ thickness at room temperature. The neat resin composite plate was also made with the above dimension without any reinforcement. Suitable pieces of the above were cut from the composite plates for erosion studies. Six groups of laminate composite samples with total 4 plies were manufactured by varying stacking sequence of jute and glass fabrics as presented in Table.1.

Table 1. Laminate stacking sequence

\begin{tabular}{|c|c|c|c|c|c|c|}
\hline \multirow{2}{*}{ Symbol } & \multirow{2}{*}{$\begin{array}{c}\text { Stacking } \\
\text { sequence }\end{array}$} & \multicolumn{2}{|c|}{ Wt\% of Fibers } & \multicolumn{2}{c|}{ Total Fiber } & \multirow{2}{*}{$\begin{array}{c}\text { Thickness } \\
\text { (mm) }\end{array}$} \\
\cline { 3 - 6 } & & Jute & Glass & $\begin{array}{c}\text { Weight } \\
\text { fraction (\%) }\end{array}$ & $\begin{array}{c}\text { Volume } \\
\text { fraction (\%) }\end{array}$ & 5.0 \\
\hline S1 & JJJJ & 100 & 00 & 60.69 & 54.40 & 4.4 \\
\hline S2 & JJGJ & 75 & 25 & 65.60 & 56.36 & 4.2 \\
\hline S3 & JJGG & 50 & 50 & 66.00 & 53.33 & 5.0 \\
\hline S4 & JGJG & 50 & 50 & 57.96 & 44.80 & 4.5 \\
\hline S5 & JGGJ & 50 & 50 & 62.73 & 49.78 & 4.4 \\
\hline S6 & GJJG & 50 & 50 & 63.79 & 50.91 & \\
\hline
\end{tabular}

Jute and glass fabrics were pre-impregnated with the matrix material consisting of epoxy resin and hardener in the ratio of 10:1. Care was taken to avoid formation of air bubbles during pouring. Pressure was then applied from the top and the mold was allowed to cure at room temperature for $72 \mathrm{hrs}$. During the application of pressure some polymer squeezes out from the mould. For this, care has already been taken during pouring. After $72 \mathrm{hrs}$ the samples were taken out of the mold, after curing the laminate was cut into required size of erosion by diamond cutter. In the present case the composites prepared were consists of $62 \mathrm{wt} \%$ fiber. The total fiber volume fraction is calculated using equation 1. 


$$
V_{f}=\frac{\left(W_{j} / \rho_{j}\right)+\left(W_{g} / \rho_{g}\right)}{\left(W_{j} / \rho_{j}\right)+\left(W_{g} / \rho_{g}\right)+\left(W_{r} / \rho_{r}\right)}
$$

Where $W j, W g$ and $W r$ are the known weights of the jute, glass and resin, respectively, and $\rho_{j,} \rho_{g}$ and $\rho_{r}$ are the densities of jute, glass and resin, respectively. The density of epoxy resin, jute and glass fiber is found to be $1.0974 \mathrm{~g} / \mathrm{cm}^{3}, 1.42 \mathrm{~g} / \mathrm{cm}^{3}$ and 2.55 $\mathrm{g} / \mathrm{cm}^{3}$ respectively.

\section{Erosion wear test}

The solid particle erosion experiments were carried out as per ASTM G76 standard on the erosion test rig shown in Figure 1.

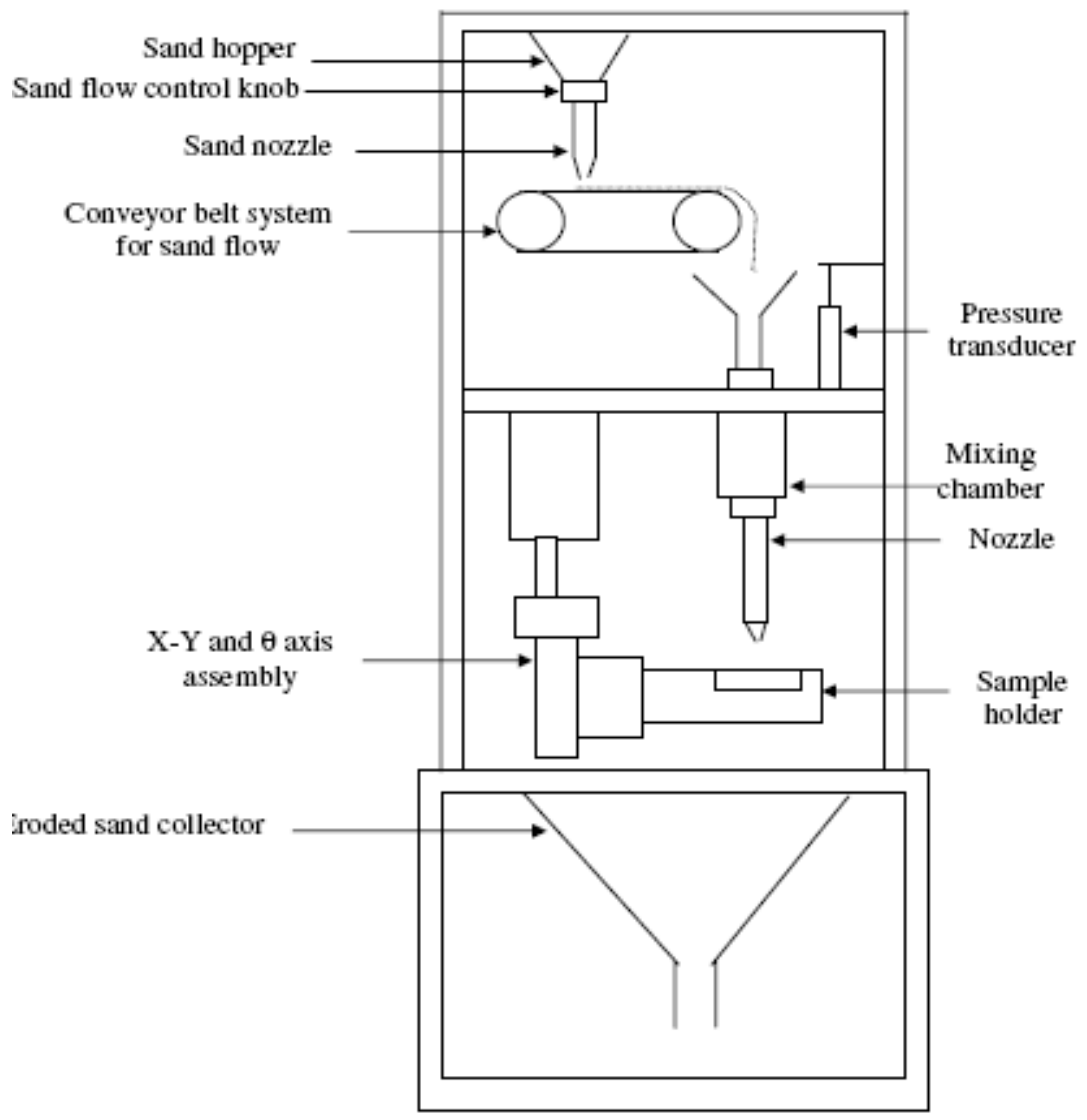

Figure 1. Schematic diagram of erosion test rig

The test rig consist of an air compressor, an air drying unit, a conveyor belt type particle feeder and an particle mixing and accelerating chamber. The dried and compressed air is mixed with silica sand $(150-250 \mu \mathrm{m}$ size $)$ which was feed constantly by conveyor belt feeder into the mixing chamber. Samples of composite $(30 \mathrm{~mm}$ x $30 \mathrm{~mm}$ x $3 \mathrm{~mm}$ ) were held at selected angles $\left(30^{\circ}, 45^{\circ}, 60^{\circ}\right.$ and $\left.90^{\circ}\right)$ with respect to flow of the impinging sand particles and eroded. The silica particles were accelerated by passing through a converging tungsten carbide nozzle of $4 \mathrm{~mm}$ diameter to bombard the target. The distances between the target material and nozzle was approximately $10 \mathrm{~mm}$. By changing the pressure the compressed air results in the variation of the impact velocity of the particles. The velocity of the eroding particles was determined using a rotating disc method. Wear was measured by weight loss method. Samples were cleaned with acetone before and after each test. Eroded samples were cleaned with a brush to remove fine sand particles attached to the surface and then wiped with a cotton plug dipped in acetone to avoid any air entrapment of wear debris in the samples. The wear rate was expressed in terms of $\Delta W c(\mathrm{~g}) / \Delta W s(\mathrm{~g})$; where $\Delta W c$ loss of weight of composites and $\Delta W s$ total weight of erodent used. $\Delta W c$ was determined by weighting the sample before and after each experiment on a weighting balance having an accuracy of $0.001 \mathrm{mg}$. The experimental detail is presented in Table 2 .

Table 2. Test parameters 


\begin{tabular}{|l|l|}
\hline Erodent & Silica sand \\
\hline Erodent size $(\mu \mathrm{m})$ & $200 \pm 50$ \\
\hline Impingement angle $\left(\alpha^{0}\right)$ & $30,45,60,90$ \\
\hline Impact velocity $(\mathrm{m} / \mathrm{s})$ & $48,70,82$ \\
\hline Erodent feed rate $(\mathrm{g} / \mathrm{min})$ & 4 \\
\hline Test temperature & $\mathrm{RT}$ \\
\hline Nozzle to sample distance $(\mathrm{mm})$ & 10 \\
\hline Nozzle diameter & 4 \\
\hline Time & $5 \mathrm{~min}$. \\
\hline
\end{tabular}

\section{Microhardness}

The present investigation reveals that the by varying the number and position of glass and jute layers six different stacking sequences are obtained. As shown in Figure 2 the composite micro-hardness is different for different stacking sequences. Its maximum value is for sequence $\mathrm{S} 4$.

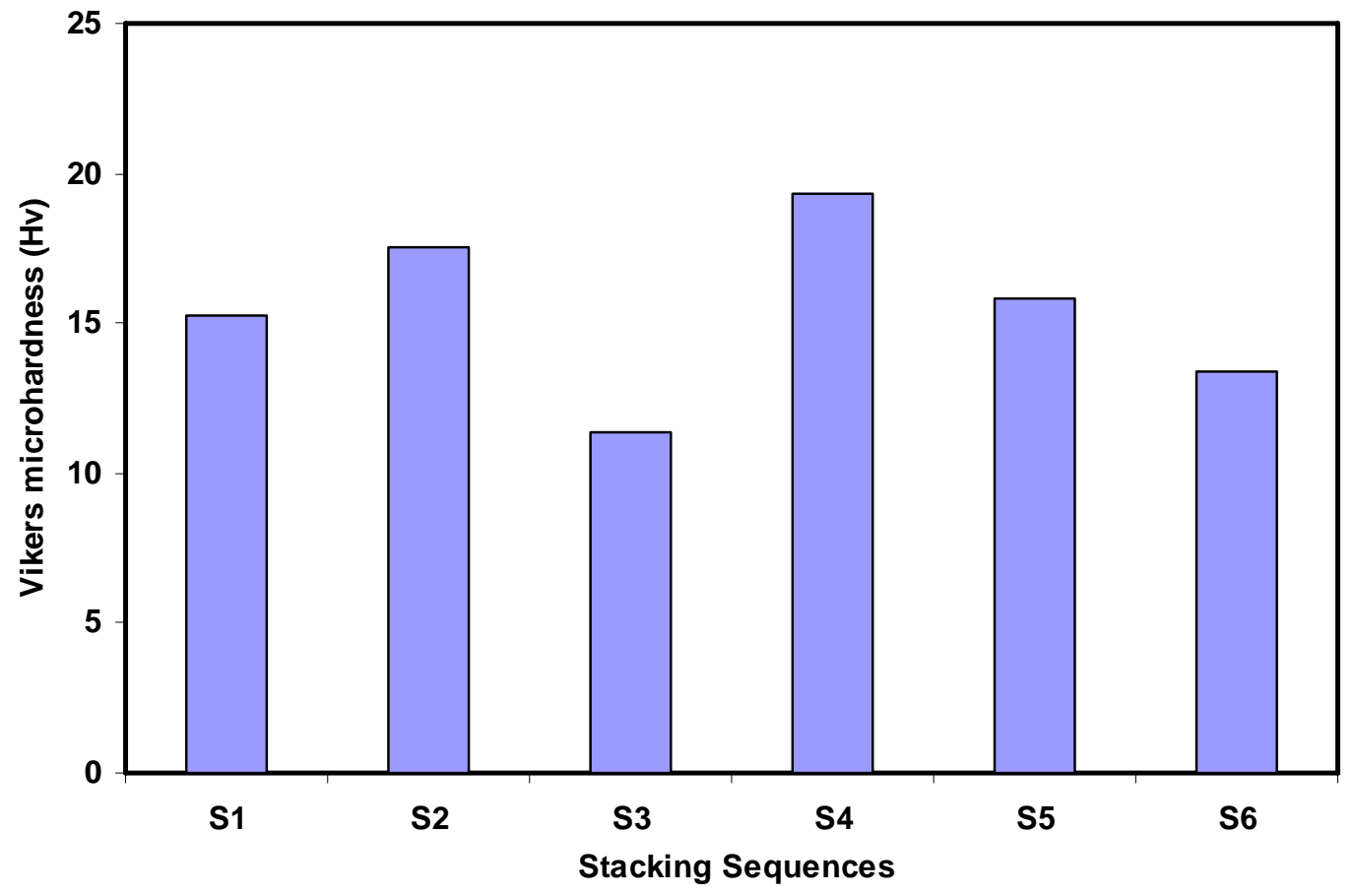

Figure 2. Effect of Hardness on stacking sequence in epoxy composites 


\section{Influence of impingement angle on erosion wear behavior}

Figure 3-5 shows the influence of impingement angle $(\alpha)$ on the erosion rate of jute E-glass epoxy and its composites. This shows that peak erosion takes place at impingement angle of $45^{\circ}$ for the composites. It is known that impingement angle is one of the most important parameters for the erosion behavior of materials. In the literature materials as classified as ductile or brittle based on the dependence of their erosion rate with impingement angle. The ductile behavior is characterized by maximum erosion rate at low impingement angle typically $15^{\circ}<\alpha<30^{\circ}$. On the other hand, if the maximum erosion rate occurs at normal impact $\left(\alpha=90^{\circ}\right)$ the behavior of the material is brittle. Reinforced composites have been found to exhibit semi ductile behavior with maximum erosion rate at intermediate impingement angles; typically $\left(45^{0}<\alpha<60^{\circ}\right)$. However the above classification is not absolute on the erosion behavior of materials which strongly depends upon the experimental conditions and the composition of target materials. Therefore maximum erosion rate at $45^{\circ}$ in the present case indicates that these composites are neither behaving in a purely ductile nor in a purely brittle manner. So this behavior of these composites can be termed as semi-ductile in nature.

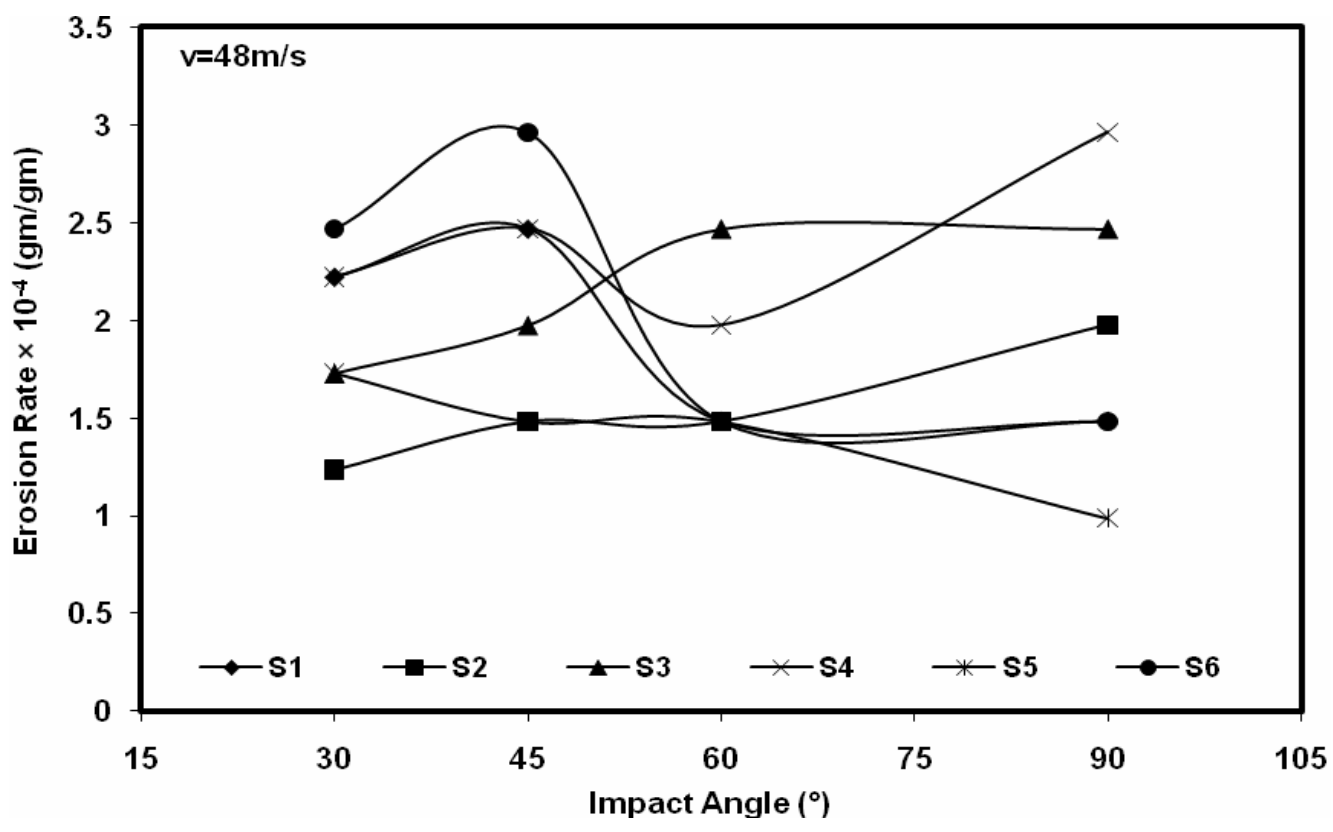

Figure 3. Variation of erosion rate with different impingement angle at velocity $48 \mathrm{~m} / \mathrm{s}$

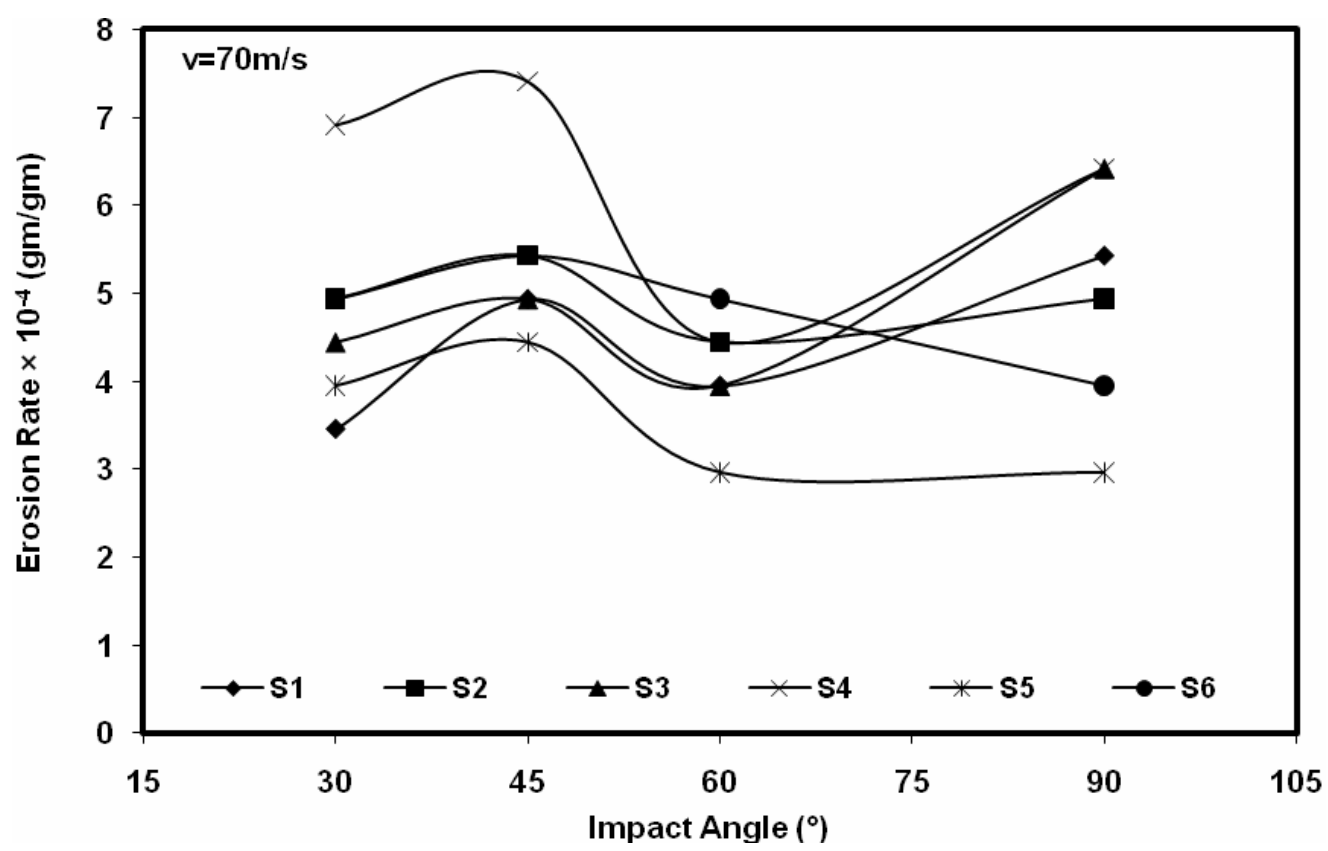

Figure 4. Variation of erosion rate with different impingement angle at velocity $70 \mathrm{~m} / \mathrm{s}$ 


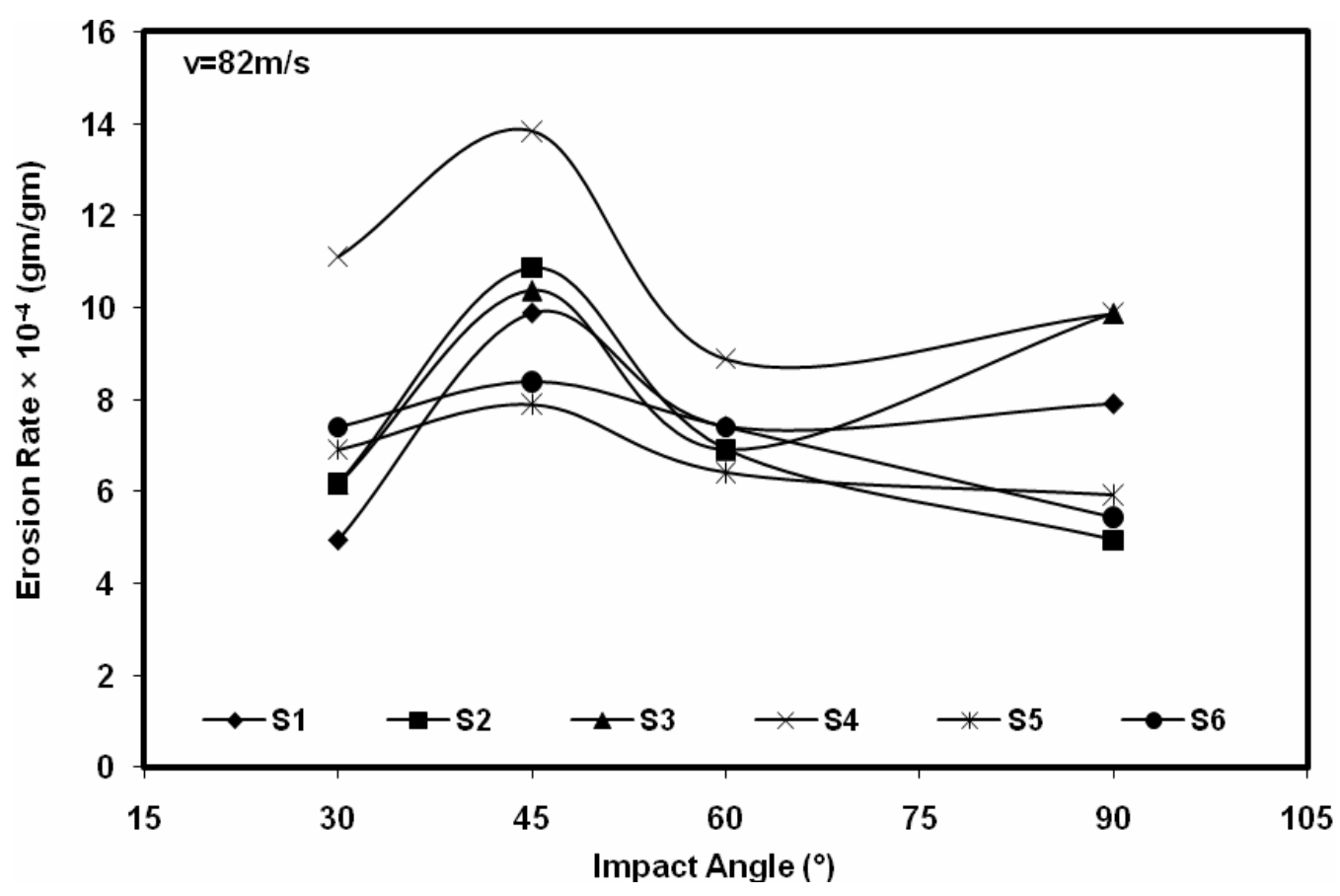

Figure 5. Variation of erosion rate with different impingement angle at velocity $82 \mathrm{~m} / \mathrm{s}$

\section{Surface morphology of eroded surface}

Figure 6 (a) shows the crater formed and the damage caused to the composite. It shows extensive damage of fibers but still fibers are not pullout from the matrix. When the damage enters the glass fiber layers Figure 6(b), it breaks the fibers but chipping up of fibers from the matrix is prevented. It can be justified from this fact that erosion resistance of the natural fiber jute can be improved significantly by placing the synthetic fiber at the middle.

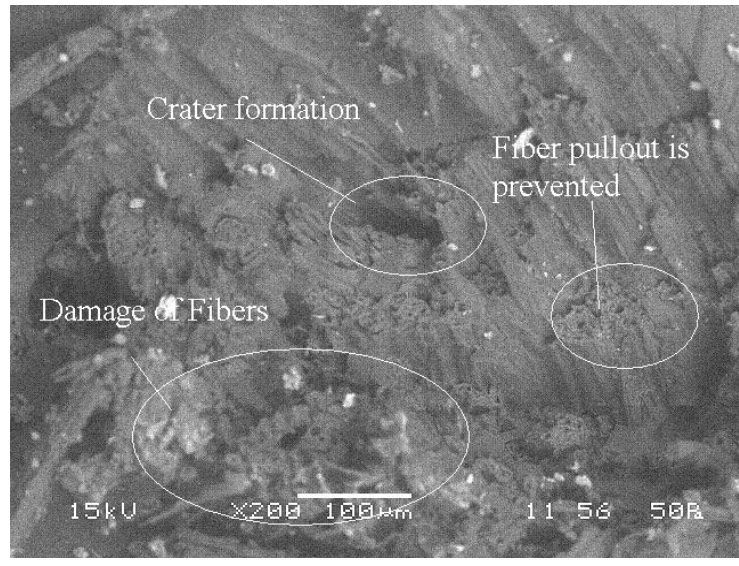

(a) Jute (Extreme layer)

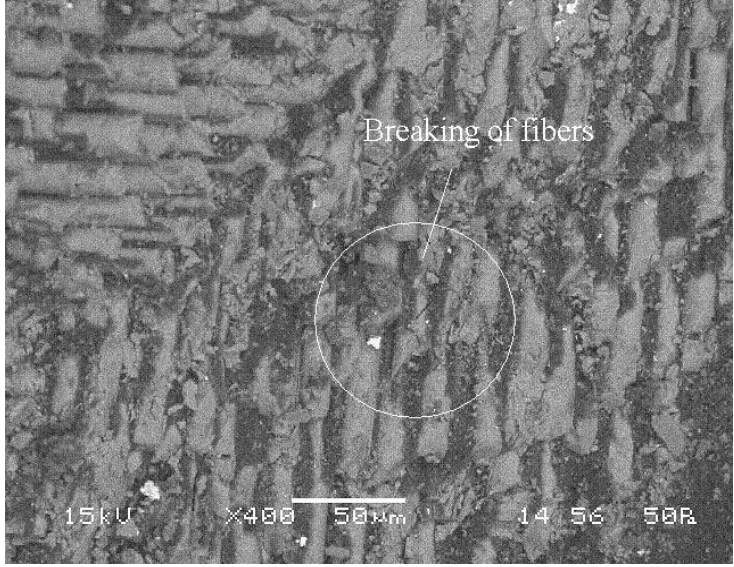

(b) Glass (Intermediate layer)

Figure 6. Micrographs of eroded samples for stacking sequence $\mathrm{S}_{5}$

\section{Conclusion}

Experiments were carried out to study the effect of jute and glass fiber stacking sequence on the erosion rate of jute E-glass epoxy and its composites with silica sand as erodent. Based on the results the following conclusions are drawn.

1. Incorporation of glass in jute fiber composite enhances the erosive properties of resulting hybrid composite.

2. Layering sequence (altering the position of glass piles) significantly affects the erosive strength. 
3. For the same relative weight fraction of jute and glass fiber, layering sequence has significant effect on erosive wear properties.

4. The erosive wear of sample (S5) with two glass layers between jute layers at extreme ends gives the lowest value.

5. The influence of impingement angle on erosive wear of all composites under consideration exhibit semi ductile behavior with maximum wear rate at $45^{0}$ impingement angle.

6. It is clear from this study that erosive strength of natural fiber (Jute) can be increased by hybridization with synthetic fiber.

\section{References}

Barkoula N. M., Karger Kocsis. 2002. Effect of fiber content and relative fiber orientation on the solid particle erosion of GF/PP composite, Wear, Vol. 252, pp. 80-87.

Bijwe J., Indumathi J., Ghose A.K. 2002. On the abrasive wear behavior of fabric-reinforced polyetherimide composites, Wear, Vol.253, pp. 768-777.

Bijwe J., Indumathi J., John Rajesh J., Fahim M. 2001. Friction and wear behavior of polyetherimide composites in various wear modes, Wear, Vol.249, pp. 715-726.

Das S., Mondal D.P., Modi O. P., Dasgupta R. 1999. Influence of experimental parameters on the erosive-corrosive wear of AlSiC particle composite, Wear, Vol. 231, No.2, pp. 195-205.

Das S., Saraswathi Y. L. and Mondal D. P. 2006. Erosive-corrosive wear of Aluminium alloy composites: Influence of slurry composition and speed, Wear, Vol. 261, No.2, pp. 180-190.

Hager A., Friedrich K., Dzenis Y A., Paipetis S. A. 1995. Study of erosion wear of advanced polymer composites. In: Street K, editor. ICCM-10 Conference proceedings, Whistler, BC, Canada. Cambridge (UK): Wood head Publishing; pp. 155-162.

Harsha A. P., Thakre A.A. 2007. Investigation on solid particle erosion behaviour of polyetherimide and its composites, Wear, Vol.262, pp. 807-818.

Hussainova I., Kubarsepp J., Shcheglov I.1999. Investigation of impact of solid particles against hard metal and cermet targets, Tribology International, Vol. 32, No.6, pp. 337-344.

Miyazaki N., Takeda T. 1993. Solid particle erosion of fiber reinforced plastics, Journal of Composite Materials, Vol.27, pp. 2131.

Neville A., Reza F., Chiovelli S., Revega T. 2005. Erosion-corrosion behaviour of WC based MMCs in liquid-solid slurries, Conference on Wear of materials, Vol.259, No.1-6, pp. 181-195.

Rajesh John J.,Bijwe J., Tewari U.S. and Venkataraman. 2001. Erosive wear behavior of various polyamides, Wear, Vol.249, pp.702-714.

Roy M., Vishwanathan B., Sundararajan G. 1994. The solid particle erosion of polymer matrix composites. Wear, Vol.171, pp. 149-161.

Sabeel A.K., Vijayarangan S. 2008. Tensile, flexural and inter laminar shear properties of woven jute and jute-glass fabric reinforced polyester composites, Journal of Materials Processing Technology, Vol.207, No.1-3, pp. 330-335.

Santulli C., Caruso A.P. 2009. A Comparative Study on Falling Weight Impact Properties of Jute/Epoxy and Hemp/Epoxy Laminates, Malaysian Polymer Journal, Vol.4, No.1, pp. 19-29.

Sari N. and Sinmazcelik T. 2007. Erosive wear behaviour of carbon fiber polyetherimide Composites under low particle speed, Materials and Design, Vol. 28, No.1, pp. 351-355.

Srivastava V.K., Prakash R., Shembekar P.S. 1988. Fracture behaviour of fly ash filled FRP composites. Composite Structure, Vol.10, pp. 271-279.

Tewari U. S., Harsha A. P., Hager A. M., Friedrich K. 2003. Solid particle erosion of carbon fiber- and glass fiber-epoxy composites, Composites Science and Technology, Vol.63, pp. 549-557.

\section{Biographical notes}

B.C.Patel is an Asst-Professor in the department of Mechanical Engineering,SES ,Sundargarh.He has 15 years of teaching Experience. His areas of interest is Composite material.

Dr. S.K Acharya is an Associate Professor in the Department of Mechanical Engineering, National Institute of Technology Rourkela, India. He has more than 24 years of experience in teaching and research. His current area of research includes Tribology, Composite materials and Nano Technology. He has published more than thirty papers in referred national and international journals. He has also presented more than seventy five research articles in national and international conferences.

Dr. D. Mishra is the Professopr in Mechanical Engineering Department, VSSUT, Burla, ORISSA, INDIA .He is currently Head of the Department of manufacturing Science .He has got 15 years of teaching experience. He has published about 25 Research papers in referred national and international journals. He has also presented more than thirty research articles in national and international conferences.

Received March 2011

Accepted May 2011

Final acceptance in revised form May 2011 